\title{
Ensemble of Small Models As a Tool For Alien Invasive Species Management Planning: Evaluation of Vespa Velutina (Hymenoptera: Vespidae) Under Mediterranean Island Conditions
}

\section{Cayetano Herrera}

Universitat de les Illes Balears

José A. Jurado-Rivera ( $\nabla$ jose.jurado@uib.es )

Universitat de les Illes Balears https:// orcid.org/0000-0003-0999-2803

Mar Leza

Universitat de les Illes Balears

\section{Research Article}

Keywords: Biological invasion, Ecological niche models, Ensemble of small models, Vespa velutina, Mallorca, Mediterranean islands

Posted Date: September 17th, 2021

DOl: https://doi.org/10.21203/rs.3.rs-809089/v1

License: (c) (1) This work is licensed under a Creative Commons Attribution 4.0 International License. Read Full License

Version of Record: A version of this preprint was published at Journal of Pest Science on March 11th, 2022. See the published version at https://doi.org/10.1007/s10340-022-01491-7. 


\section{Abstract}

Ecological niche models have proved to be a powerful tool in assessing invasiveness risk of alien species, allowing the optimization of control strategies. Vespa velutina (Hymenoptera: Vespidae) is an invasive species with strong ecological, economical and health impacts in Europe after it first report in France in 2004. It was detected for the first time in a Mediterranean island (Mallorca, Balearic Islands, Spain) in 2015, where a single nest was found in the northwest of the island. Immediately a control plan was implemented. In this study, we analysed 30 occurrence data in Mallorca island to assess the suitability distribution predicted to Mediterranean island conditions using ensemble of small models. We obtained high values of AUC (0.9165), Somers' D (0.8331), Boyce (0.7611) and TSS (0.7754) as quality parameters of the final ensembled model. We show for the first time that there are suitable areas where this species can expand and stablish, mainly in steeper slopes and low isothermality zones. Likewise, the distribution suitability of $V$. velutina for other Mediterranean islands (Ibiza, Formentera, Menorca, Corsica, Sardinia, Sicily, Crete and Cyprus) was also explored, showing potentially suitable zones. This study provides valuable information regarding the areas in the Mediterranean islands under risk of invasion, and it could be used by both scientists and managers for an early detection and control of the invasive species due to its cost-effectiveness in terms of conservation.

\section{Introduction}

The increases of human mobility and global trade over the last years have resulted in an unprecedented number of invasions and establishment of invasive species all around the world (Levine and D'Antonio 2003; Sardain, Sardain, and Leung 2019), with severe environmental and socioeconomic impacts (Beggs et al. 2011; Paini et al. 2016; Requier et al. 2019). In particular, social Hymenoptera have great success in establishing populations after introduction, because of they have excellent dispersal abilities, high reproductive rates, broad diets and habitat ranges, effective predator defences, and superior competitive abilities, which enhance their ability to establish, spread and have a major impact on native ecosystems once they arrive in a new region (Beggs et al. 2011; Moller 1996).

The yellow-legged hornet (Vespa velutina Lepeletier 1836) is an invasive alien hymenoptera species which was accidentally introduced in Europe from Asia (Laurino et al. 2020). It was reported for the first time in south-west France in 2004 and rapidly spread to nearby European countries (Laurino et al. 2020).

The main impact of the yellow-legged hornet is the likely decrease in honeybee (Apis mellifera) populations (Monceau et al. 2013), preying also upon other pollinators and insects (Rojas-Nossa and Calviño-Cancela 2020; Rome et al. 2011). This invasion could be devastating for island ecosystems, considering the situation of the populations of honeybees (Dainat, vanEngelsdorp, and Neumann 2012; Ellis, Evans, and Pettis 2010), the fragility of the ecosystem (Traveset et al. 2019) and the impact on endemic insects (Ikegami et al. 2020). In addition, it is possible that the yellow-legged hornets attack humans when colonial nests are established in nearby areas, producing poison and allergy cases (de Haro et al. 2010; Herrera, Leza, and Martínez-López 2020). 
In the case of Mallorca (Balearic Islands, Spain) an individual of this species was detected in 2015, being the first report of this invasive hornet in a Mediterranean island (Laurino et al. 2020). This individual was taken to the department of Biology of the University of the Balearic Islands where it was identified. Together with the local authorities, an intensive protocol to detect and remove nests was implemented, as described in Leza et al. (2021). In 2015, only one nest was found in the northwest of the island. During 2016, nine additional nests were detected and removed, and in 2017 the number of reported nests increased to twenty. Since then no more secondary nests were found (Leza et al. 2021), being the first territory where $V$. velutina has been officially eradicated (CAIB 2019).

A recent spread modelling study (Robinet, Darrouzet, and Suppo 2019) suggests that $V$. velutina can not naturally colonize Mediterranean islands (such as Sicilia, Sardinia, Mallorca or Corsica) by their own but can be introduced it by human-mediated dispersal. Hence, the incursion in Mallorca was probably due to an accidental introduction by humans (Robinet, Darrouzet, and Suppo 2019).

It is known that invasive species often do not present a static niche; Broennimann et al. (2007) provided the first empirical evidence that an invasive species can occupy climatically distinct niche spaces after its introduction into a new area. Therefore, anticipating potential distributions of invasive species is essential for prioritization, early detection and control (Broennimann et al. 2007), and indispensable for a conservation plan (Peterson and Robins 2003).

Ecological niche models (Guisan and Thuiller 2005) have been used to predict the invasion extents from a great diversity of invasive organisms, such as plants (Broennimann et al. 2007), fishes (Zengeya et al. 2013), birds (Ancillotto et al. 2016), snakes (Pyron, Burbrink, and Guiher 2008) and insects (Alaniz, Carvajal, and Vergara 2021; Muirhead et al. 2006). The precision of such models increases with sample size, the higher the number of presences, the better the niche description (Hernandez et al. 2006). This is one of the main drawbacks of the application of these approach in recent invasions where the occurrences may be scarce, which can lead to model overfitting and thus limiting its applicability (Vaughan and Ormerod 2005). Under this scenario, the ensemble of small models has arisen as a novel and robust strategy to predict the distribution of species accounting for few occurrences (Breiner et al. $2015,2018)$. Spite of their usefulness, this methodology has been low applied in the context of invasive species, where just two studies were found in the literature: modelling an invasive squirrel (Di Febbraro et al. 2019) and a chytrid fungus (Beukema et al. 2018).

Here we aim to identify the ecological factors determining the presence of $V$. velutina and to predict potentially suitable areas of invasion under Mediterranean island conditions. To do so, we compiled the distribution of all secondary nests in Mallorca to calibrate ecological niche models using ensemble of small models. In addition, we expand our calibrated ecological niche models to other Mediterranean islands still free from V. velutina (e.g. Ibiza, Formentera, Menorca, Corsica, Sardinia, Sicily, Crete and Cyprus) to identify areas susceptible to being colonized. This case study might assist the management and control of this alien invasive species by using a novel ecological niche modelling strategy for species with few occurrences. 


\section{Material And Methods}

\section{Study site, presence data of $\mathrm{V}$. velutina and environmental variables}

Mallorca $\left(39^{\circ} 30^{\prime} \mathrm{N}, 03^{\circ} \mathrm{O}^{\prime} \mathrm{E}\right)$ is the biggest island of the westernmost Mediterranean archipelago (Balearic Islands) and is climatically considered Mediterranean (based on Emberger's Index). The first specimen was detected in the northwest of the island (Leza, Miranda, and Colomar 2018). This area is characterized by specific climatic and geomorphological conditions compared to the rest of the regions in Mallorca, such as the highest precipitation rate (1400-1600 mm annual) and cooler temperatures. Consequently, its vegetation is quite different from the rest of the island, and is dominated by pine trees (Pinus halepensis Miller), holm oaks (Quercus ilex L.), garrigue (mainly Salvia rosmarinus (L.) Schleid and Erica multiflora L.), wild olive trees (Olea europaea var. sy/vestris L.), orchards of orange trees (Citrus sinensis (L.) Osbeckand) and olive trees (Olea europaea L.). (Leza et al. 2021).

Since the first detection of $V$. velutina in Mallorca, intensive surveys have been implemented in order to detect all nests in the area based on bait traps and public reports on the presence of adults. When an adult was detected, feeding points with protein attractant (raw fish) were set in the area to identify the direction that these adults took and to triangulate the precise nest location with GPS for subsequent removal at night (Leza et al. 2021; Leza, Miranda, and Colomar 2018). This work program was implemented for 6 years (2015-2020) resulting in the record of 30 secondary nest's locations.

A total of 42 environmental belonging to five main categories where included in the analysis: climatic, topographic, remote sensing, hydrography and anthropogenic (Table 1, Supplementary material) (BarbetMassin et al. 2012; Bertolino et al. 2016; Bessa et al. 2016; Fournier et al. 2017; Lioy et al. 2019; de Medeiros, Hernández-Lambraño, and Sánchez Agudo 2018; Robinet, Darrouzet, and Suppo 2019; Rodríguez-Flores et al. 2019; Villemant et al. 2011; Villemant, Muller, and Haubois 2011). Mallorca island was divided into cells of $1 \mathrm{~km}^{2}$ and all variables were aggregate by average to a resolution of this $1 \mathrm{~km}^{2}$. Multicollinearity among the 42 variables was assessed and eight uncorrelated predictors, and VIF less than 4, were selected: continentality, human footprint, isothermality, land cover, precipitation of the coldest quarter, precipitation of the warmest quarter, precipitation seasonality and slope (Table 1 and Fig. 1, Supplementary material).

\section{Ecological suitability modelling}

It is recommended to include different models from different modelling techniques as it cannot be guaranteed that a particular method is the best for all situations (Hirzel and Le Lay 2008; Johnson and Gillingham 2005). Hence, ten different models were selected in this study: Surface Range Envelope (SRE), Generalized linear models (GLM), Generalized additive models (GAM), Multivariate adaptive regression spline (MARS), Classification tree analysis (CTA), Flexible Discriminant Analysis (FDA), Artificial neural network (ANN), Random forest (RF), Generalized boosting method (GBM) and Maxent available in biomod2 and ecospat R packages (Broennimann, Di Cola, and Guisan 2020; Di Cola et al. 2017; Thuiller et al. 2009). 
Thirty $V$. velutina occurrence points obtained from intensive fieldwork during active nest searches (Leza et al. 2021; Leza, Miranda, and Colomar 2018), plus a random sample including the $25 \%$ of all non-invaded Mallorca cells to be used as weighted background points, were used to fit and evaluate models as described in Barbet-Massin et al. (2012). One divided by the number of cases of presences and background will provide the weight of each group (presence: $n=30$, weight $=0.0333$; background: $n=$ 1258 , weight $\left.=7.9491 \cdot 10^{-4}\right)$. The random sample was taken from the entire Mallorca island since the maximum spread distance registered for this species (78 km) (Robinet, Suppo, and Darrouzet 2017) indicates that the species could reach any point of the island from the initial invasion point. A general rule is that the sample size (number of presences) should be 10 times greater than the number of predictors included in the models (Harrell, Lee, and Mark 1996), meaning that we would need more than 80 occurrences points to avoid overfitting when including our eight environmental predictors. To circumvent this limitation we implemented the ensemble of small models (ESMs) (Breiner et al. 2015, 2018; Scherrer, Christe, and Guisan 2019; Song et al. 2019; Virtanen et al. 2018) included in ecospat R package (Broennimann, Di Cola, and Guisan 2020; Di Cola et al. 2017). This strategy involves building and evaluating many models with a small subset of predictors (Breiner et al. 2018). Finally, all simple models generated were ensembled including our eight predictors and avoiding overfitting (Breiner et al. 2018). Considering our data, 28 simple bivariate models combining the eight predictors in groups of two were generated. Each small model was fitted with $2 / 3$ of data and evaluated with $1 / 3$ not used to calibrate the model, cross-validation based on AUC index (Benito et al. 2017; Pearson et al. 2007) and using ecospat $R$ package (Broennimann, Di Cola, and Guisan 2020; Di Cola et al. 2017). We applied this methodology 100 times to each single bivariate model and we used the following parameters to evaluate model performance: Area under the curve (AUC), Somers'D ( $D=2 \cdot(A \cup C-0.5)$ ), Boyce Index (Boyce) and True skill statistic (TSS) (Allouche, Tsoar, and Kadmon 2006; Boyce et al. 2002; Newson 2006; Somodi, Lepesi, and Botta-Dukát 2017). Finally, we ensemble each small model using Somers'D weighted average (Breiner et al. 2015), where those models with AUC lower than 0.5 (Somer's $D=0$ ) were not included in the final ensemble.

\section{Response curves}

For each climate variable, the predicted suitability over all values in the gradient of the variable was generated while the other climate variables were kept at their average values. Then, the predicted values against the climate gradient were plotted, which represents the response of the species to the climate variable (Elith et al. 2005).

\section{Importance of environmental factors}

The sum of weights of bivariate models for each variable was calculated. This value was compared with the sum of weights of all bivariate models to determine the importance of each environmental factor. This procedure was performed for each method applied. Finally, for ensemble models, the contributions were weighted means of the different methods (Broennimann, Di Cola, and Guisan 2020). 


\section{Measuring ecological niche}

In order to measure the ecological niche occupied by $V$. velutina from the invaded range along the three years with active invasion (2015-2017) under Mediterranean island conditions, sets of environmental variables of the $25 \%$ random background study area and $V$. velutina occurrences were subjected to $2 \mathrm{D}$ PCA. The final 2D-PCA was plotted with ellipses (95\% confidence) and marginal box plots which represent spatial niches offered and occupied (Janekovi and Novak 2012). Finally, Kruskal-Wallis test was used to check for statistical differences between background and $V$. velutina niches.

\section{Transferability assessment}

We explored the potential suitability of $V$. velutina in the largest Mediterranean islands (Corsica, Crete, Cyprus, Formentera, Ibiza, Menorca, Sardinia, and Sicily). For this purpose, the same environmental variables to a resolution of $1 \mathrm{~km}^{2}$ used for model's calibration, were obtained for each island. Consecutively, the ecological niche model calibrated in Mallorca was projected in each island with its own environmental data. On the other hand, maritime ports were indicated for each island in order to detect nearby suitable areas where $V$. velutina could expand if it was detected. Likewise, Multivariate Environmental Similarity Surface (MESS) was applied in the final ensemble model for each island. This analysis determines how similar are the conditions of the other Mediterranean islands, in relation to the calibration conditions of the model in Mallorca (Elith, Kearney, and Phillips 2010).

\section{Results}

\section{Ecological suitability modelling}

After fitting and evaluating 100 times each single bivariate model from 28 different combinations of predictors and using 10 different methods, we obtained a final dataset of 28000 single bivariate models. Then, a total of 694 single bivariate models were removed because AUC was lower than 0.5. Finally, the final ensemble model was obtained from 27306 models using Somers'D weighted average.

We obtained high values of AUC for all models $\left(A U C_{\min }=0.673\right)$ as well as for Somers'D (Somers' $D_{\min }=$ 0.345), a rescaled version of the AUC. Moreover, models showed high values of TSS $\left(\right.$ TSS $_{\min }=0.395$ ) (Fig. 1) whereas Boyce Index showed more dispersal scores but always above 0, despite three SRE models which were equal or lower than 0 . Finally, for the final ensemble model, we obtained a high value weighted mean of AUC $(0.9165 \pm 0.032)$, Somer's D $(0.8331 \pm 0.0631)$, Boyce $(0.7611 \pm 0.102)$ and TSS $(0.7754 \pm 0.0701)$ (Fig. 1).

The corresponding potential distribution obtained from the ensemble model (Fig. 2) identifies Mallorca as an area of low suitability of $V$. velutina with a mean suitability of $0.045 \pm 0.0656$ (range $0.007-0.4530$ ) for the entire island. Nonetheless, the westernmost mountain range presents higher values, reaching until 0.4530 as a maximum suitability. The suitability of the location where the first hornet nest was discovered in 2015 was estimated to be 0.239 . Since then, the mean suitability for 2016 was $0.3344 \pm$ 
0.0784 (range $0.1780-0.4330$ ) and $0.2994 \pm 0.0897$ (range 0.1100-0.4530) for 2017. As an average, a mean suitability for all located nests was $0.3046 \pm 0.0864$ (range $0.1100-0.4530$ ) after three years of active invasion.

\section{Response curves}

According to the response curves (Fig. 3), land cover and the precipitation of the coldest quarter were centred. Slope and continentality showed right-skewed response curves whereas precipitation of the warmest quarter, isothermality and precipitation seasonality showed left-skewed response curves. Finally, human footprint was stable across the gradient.

Sites occupied by $V$. velutina showed a land cover from rainfed croplands (GlobCover 2009 value: 14.00) to shrubland (GlobCover 2009 value: 130.62), and a human footprint from 30.29 to $88.32 \%$. Slope varied between 0.69 and $28.87^{\circ}$, characterized by a high slope diversity. The range of the precipitation of the warmest quarter was around $53.00 \mathrm{~mm}$ and the range of the coldest quarter was $100.00 \mathrm{~mm}$. The range of isothermality was around $7.00^{\circ} \mathrm{C}$ and precipitation seasonality was $4.23 \%$. Finally, the continentality varied $0.4^{\circ} \mathrm{C}$ (Table 1). The comparison between the distributions of the presence and the background data showed high use versus availability in sites with higher average human footprint and precipitation of the coldest quarter (Fig. 2, Supplementary material). Nonetheless, the other ecological factors present a lower use versus availability, suggesting that these variables could limit its distribution (Fig. 2, Supplementary material).

\section{Importance of environmental factors and measuring ecological niche}

The analysis of variable importance showed that the most important predictor was slope (0.1452), followed by isothermality (0.1424) (Table 1). Moreover, the 2D-PCA analyse revealed that the Dim 1 and the Dim 2 explained $38.2 \%$ and $22.9 \%$ of the total variance. Hence, the final 2D-PCA explained $61.1 \%$ of the total variance with statistical differences between background and $V$. velutina niches in Dim 1 ( $p$ value < 0.05) (Fig. 4). The most important variables in the Dim 1 were Slope (27.70) and Isothermality (23.81), as in the analysis of variable importance during modelling.

\section{Transferability assessment}

The results show a potential mean suitability higher in the other largest Mediterranean islands than in Mallorca for $V$. velutina. Specifically: Ibiza $0.07437 \pm 0.02666$ (range 0.0100-0.1910), Menorca $0.07139 \pm$ 0.01665 (range 0.0300-0.1270), Corsica 0.1182 \pm 0.04053 (range 0.0180-0.2740), Sardinia $0.1252 \pm$ 0.03668 (range 0.0240-0.3150), Sicily $0.1251 \pm 0.04433$ (range 0.0300-0.3180), Crete $0.1375 \pm 0.03444$ (range 0.0640-0.2650) and Cyprus $0.1347 \pm 0.02671$ (range 0.0520-0.2550) (Fig. 5). However, any of the potential suitability values in these islands reached the high values found in some points of Mallorca (maximum suitability value $0.4530 ;$ Fig. 3). Finally, MESS analysis reported similar ecological conditions to Mallorca in Ibiza, Corsica and Sardinia (Fig. 5). 


\section{Discussion}

It is known that invasive species often do not present a static niche. This niche can expand, contract or change, reducing the predictive capacity of distribution models based on niche conservatism for species with a dynamic niche (Becerra López et al. 2017; Broennimann et al. 2007; Fitzpatrick et al. 2006; Pearman et al. 2008). For this reason, we integrally georeferenced the population of $V$. velutina from Mallorca (Balearic Islands) (Leza et al. 2021) and developed a predictive model for the entire island to obtain a distribution map of the habitat suitability with management purposes (Peterson, Papes, and Kluza 2003). Furthermore, the high population density and dispersion rate of this invasive species highlight the real necessity for an early detection and eradication measures. This need is even more pronounced in biodiversity hotspots like Mallorca, which account for high endemicity levels that may be threatened by alien invaders (Bessa et al. 2016).

To achieve it, we used a specific strategy for the species distribution model with few occurrences (Breiner et al. 2018) which has been low used in the management of invasive species (Beukema et al. 2018; Di Febbraro et al. 2019). These studies cited before showed this methodology had good results for assessing the invasiveness of an alien species in a territory, representing an important step forward to define their potential spread and provide a sound base for prioritize management actions.

Our case study represents the first time that $V$. velutina species reaches a Mediterranean island after its arrival to Europe in 2004 (Haxaire, Bouguet, and Tamisier 2006), and despite accounting for few occurrences it has been possible to determine its optimum niche in the first stages of invasion for an area that, a priori, seems to be low suitable (Villemant et al. 2011).

As a general view a great part of the island appears less suitable for $V$. velutina (Fig. 2), in agreement with previous studies reporting the low suitability of the Mediterranean environments (Barbet-Massin et al. 2013; Villemant et al. 2011). Nonetheless, our distributional model calibrated under Mediterranean island conditions proves that there are suitable areas for the establishment of $V$. velutina (most part of "Serra de Tramuntana", $307.45 \mathrm{~km}^{2}$ ) (Fig. 2). The ecological niche model developed for the Iberian Peninsula and the Balearic Islands, based on Villemant et al. (2011), shows similar suitability values from Sóller (Mallorca) to the north of the Iberian Peninsula where this species first stablished and spread (MAGRAMA 2015). Likewise, the spread modelling developed by Robinet et al. (2019) concludes that $V$. velutina could effectively establish in Mallorca. The comparison among the above mentioned studies and our model reflects that analyzing at different scales results in different patterns, with regional scales providing more suitable areas than continental ones (as in Bessa et al., 2016). Furthermore, this hornet and other invasive terrestrial pests are mainly translocated as a by-product of shipping, where the characteristics at arrival ports could influence the invasive spread rates across territory (Hudgins, Liebhold, and Leung 2017; Sardain, Sardain, and Leung 2019). In the Mallorcan suitable area there is the port of Sóller with commercial connections with the Iberian Peninsula and France, both areas invaded by $V$. velutina (Laurino et al. 2020). Likewise, literature cites the invasion of the argentine ant (Linepithema humile) in the Balearic Islands across the same port (Bernard 1956). 
Since November 2020, V. velutina is officially eradicated in the island after two years of active searching with no detections (CAIB 2019). However, according to our results and if an early detection and eradication plan would not have been implemented, the species probably would have colonized and stablished in the entire northwest part of the island (Fig. 2), as predicted by Robinet et al. (2019). In fact, we detected an increase in the number of nests, 1 in 2015, 9 in 2016 and 20 in 2017, as in other colonized areas (Bertolino et al. 2016; Monceau and Thiéry 2016) showing the potential spreading of the pest.

Among the environmental factors used in this study (continentality, human footprint, isothermality, land cover, precipitation of the coldest quarter, precipitation of the warmest quarter, precipitation seasonality and slope), slope and isothermality were retrieved as the most important. In addition, our results show that the environmental suitability for $V$. velutina is positively correlated with slope. This topographic variable is correlated with a high number of environmental variables (Fig. 1, Supplementary material) and is known to be very useful to develop ecological models at local scale (Lassueur, Joost, and Randin 2006), since the slope affects the conditions in an organism's microclimate (Sears, Raskin, and Angilletta 2011). For example, steeper slope have been correlated with warmer core-body temperatures in butterflies (Barton and Terblanche 2014). To check the effect of the slope in $V$. velutina it will be necessary to study the development of $V$. velutina immature stages inside the nest. Moreover, installing their nest in high trees plus steeper slopes provides a higher protection against potential predators and competitors, and make it difficult to apply control measures against them. One the other hand, the great range in land cover values used by $V$. velutina shows the high adaptation capability to construct their nests in many different Mediterranean areas, such as forests, shrublands or croplands (Fig. 3) as well as in other invaded areas where this species has been successfully stablished (Carvalho et al. 2020; Franklin et al. 2017; Monceau and Thiéry 2016). Such high adaptation capability is a drawback to propose management and control measures mainly due to the great fieldwork effort needed to locate $V$. velutina colonies (Leza et al. 2021). In addition, the relationship between human footprint and suitability values suggests that disturbed habitats and human-mediated dispersal benefits this species, as reported in previous studies on similar species (Alaniz, Carvajal, and Vergara 2021; Monceau, Bonnard, and Thiéry 2014; Robinet, Darrouzet, and Suppo 2019; Robinet, Suppo, and Darrouzet 2017). The precipitation in summer (warmest quarter) was negatively correlated with suitability (Fig. 3), thus playing an important role in the pest ecology. During summer pest growths exponentially and demands high amounts of proteins (Monceau, Bonnard, and Thiéry 2014), but high precipitation values could limit its predation activity (Bista et al. 2020a, 2020b). After wintering, foundress queens emerge and start building a delicate primary nest, where site selection is closely linked to protection from adverse weather (Monceau and Thiéry 2016). Thus, the low precipitation rates typical of Mallorca during the coldest quarter benefits the spread of $V$. velutina queens in comparison with other continental areas where this species has successfully stablished (Fig. 4) (AEMET, http://www.aemet.es/). Added to all the above, response curves show minimum values in terms of seasonal variables (isothermality and precipitation seasonality) and a reduced range for continentality in terms of use $v s$ available (Fig. 2, Supplementary material), pointing to a preference for stable environments that require lower energy efforts to regulate the nest conditions (e.g., temperature and humidity). This uncertain assumption, however, needs to be addressed. 
Future studies should include density data of hives because honeybees are a quite important food resource (Bessa et al. 2016), as well as freight traffic (Lester and Beggs 2018; Pusceddu et al. 2019).

Principal component analysis (2D-PCA) of the environmental data revealed one significant axis of environmental variation, defining the suitable ecological space for $V$. velutina establishment (Fig. 4). It is important to note that since 2015 (Fig. 4, green dot) until 2017 (Fig. 4, pink dots) the ecological niche has shift, moving away from the prevailing ecological niche offered by the rest of the island, despite the overlap between background and $V$. velutina niches. This niche shift occurs along the first axis, which is associated with topography slope and isothermality gradient across the island. Supporting this idea, $V$. velutina will be able to spread and stablish in specific areas under Mediterranean conditions (Robinet, Darrouzet, and Suppo 2019).

Another important point is the approach of using niche models to predict the spread of potential invaders into new areas (Broennimann et al. 2007). Our results show that other Mediterranean islands are potentially suitable for the establishment and spread of $V$. velutina (Fig. 5), zones where this species has not been recorded yet (Laurino et al. 2020), making it necessary to implement preventive actions to avoid a possible invasion. Robinet et al. (2019) explored the human-mediated dispersal of $V$. velutina concluding that the Mediterranean islands could not be naturally colonised, this invasive species just could reach the Mediterranean islands by an accidental introduction by humans. Although the probability calculated of introducing the hornet in the Mediterranean islands is relatively low in this study: to Sicilia was $0.925 \%$, to Sardinia was $0.206 \%$, to Mallorca was $0.095 \%$ and to Corsica was $0.032 \%$ (Robinet, Darrouzet, and Suppo 2019). V. velutina reached Mallorca in spite of the low probability of introduction, so these model extrapolations is a valuable information regarding the areas in the other Mediterranean islands that might be invaded next due to it could be used by scientists and managers for an early detection of the invasive species (Fig. 5) (Broennimann et al. 2007), because it is more cost-effective outcome for conservation and can be most efficiently controlled (Holden, Nyrop, and Ellner 2016; Monceau, Bonnard, and Thiéry 2014; Robinet, Suppo, and Darrouzet 2017). There are detection and control methods for $V$. velutina across Europe, however, little has been done to date to limit its progression (Turchi and Derijard 2018) and there is no clear coordination between countries neither uniform methods for eradication since the first detection (Leza et al. 2021). Poor coordination between managers and stakeholders in France was thought to be one of the important reasons for the species continues to spread (Monceau, Bonnard, and Thiéry 2014). Hence, long-term monitoring of ports and nearby areas should be implemented for an early detection of $V$. velutina to be in time to implement a control and eradication protocol, as in Leza et al. (2021). Moreover, many studies have confirmed that citizen collaboration in control programs is essential for the best management of invasive species (Clusa et al. 2018; Graham, Henderson, and Schloss 2011; Klemann-Junior et al. 2017). In the case of V. velutina, a specific trap for this species has not yet been developed and for this reason citizen collaboration is crucial for its detection and control.

Future research will focus on the genetic characterization of the Balearic population of $V$. velutina to determine the path of introduction and to assess the role of shipping networks in spreading $V$. velutina 
across the Mediterranean Sea, which could help in promoting preventative measures such as the establishment of stringent biosecurity policies at the national, regional, and global scales.

\section{Declarations}

\section{Funding}

This work has been possible thanks to a FPI grant from the Conselleria d'Innovació, Recerca i Turisme del Govern de les IIles Balears (FPI_014_2020).

\section{Conflicts of interest}

There are no conflicts to declare regarding publication of this paper.

\section{Availability of data and material}

Not aplicable.

\section{Code availability}

The code of this study are available from the corresponding author upon reasonable request.

\section{Authors' contributions}

C. Herrera: Conceptualization; Data curation; Formal analysis; Methodology; Software; Validation; Visualization; Writing - original draft; Writing - review \& editing. J.A. Jurado-Rivera: Supervision, Validation, Visualization, Writing - review \& editing. M. Leza: Conceptualization, Supervision, Validation, Visualization, Writing - review \& editing.

\section{Ethics approval}

Not aplicable.

\section{Consent to participate}

Not aplicable.

\section{Consent for publication}

Not aplicable.

\section{Acknowledgements}

Special thanks are due to the technical staff of the working group: Servei de Protecció d'Espècies del Govern de les IIles Balears, COFIB, Agents de Medi Ambient del Govern de les IIles Balears, beekeepers and every citizen for supporting us in this study. 


\section{References}

1. Alaniz AJ, Mario A, Carvajal, Vergara PM (2021) Giants Are Coming? Predicting the Potential Spread and Impacts of the Giant Asian Hornet (Vespa Mandarinia, Hymenoptera:Vespidae) in the USA. Pest Manag Sci 77(1):104-112

2. Allouche O, Tsoar A, and Ronen Kadmon (2006) Assessing the Accuracy of Species Distribution Models: Prevalence, Kappa and the True Skill Statistic (TSS). J Appl Ecol 43(6):1223-1232

3. Ancillotto L, Strubbe D, Menchetti M, and Emiliano Mori (2016) An Overlooked Invader? Ecological Niche, Invasion Success and Range Dynamics of the Alexandrine Parakeet in the Invaded Range. Biol Invasions 18(2):583-595

4. Barbet-Massin M et al (2013) Climate Change Increases the Risk of Invasion by the Yellow-Legged Hornet. Biol Cons 157:4-10. http://dx.doi.org/10.1016/j.biocon.2012.09.015

5. Barbet-Massin M, Frédéric Jiguet, Cécile Hélène Albert, and Wilfried Thuiller (2012) "Selecting Pseudo-Absences for Species Distribution Models: How, Where and How Many?" Methods in Ecology and Evolution 3(2): 327-38

6. Barton MG, and John S. Terblanche (2014) Predicting Performance and Survival across Topographically Heterogeneous Landscapes: The Global Pest Insect Helicoverpa Armigera (Hübner, 1808) (Lepidoptera: Noctuidae). Austral Entomology 53(3):249-258

7. Becerra López J, Luis et al (2017) Evidence of Niche Shift and Invasion Potential of Lithobates Catesbeianus in the Habitat of Mexican Endemic Frogs. PLoS ONE 12(9):1-15

8. Beggs JR et al (2011) Ecological Effects and Management of Invasive Alien Vespidae. Biocontrol 56(4):505-526

9. Benito BM et al (2017) The Ecological Niche and Distribution of Neanderthals during the Last Interglacial. J Biogeogr 44(1):51-61

10. Bernard F (1956) “Remarques Sur Le Peuplement Des Baléares En Fourmis.": 254-66

11. Bertolino $S$ et al (2016) Spread of the Invasive Yellow-Legged Hornet Vespa Velutina (Hymenoptera: Vespidae) in Italy. Appl Entomol Zool 51(4):589-597

12. Bessa AS, Carvalho J, Gomes A, Santarém F (2016) Climate and Land-Use Drivers of Invasion: Predicting the Expansion of Vespa Velutina Nigrithorax into the Iberian Peninsula. Insect Conservation Diversity 9(1):27-37

13. Beukema W et al (2018) Environmental Context and Differences between Native and Invasive Observed Niches of Batrachochytrium Salamandrivorans Affect Invasion Risk Assessments in the Western Palaearctic. Divers Distrib 24(12):1788-1801

14. Bista S et al (2020a) Assessment of Hornet (Vespa Spp.) Predation on European Honeybee (Apis Mellifera L.) Apiary at Sub-Tropical Plain Areas of Parasi District, Nepal Sanjaya. Journal of Entomology Zoology Studies 8(2):746-754

15. ---. 2020b. "Incidence and Predation Rate of Hornet (Vespa Spp.) on European Honeybee (Apis Mellifera L.) Apiary at Mid-Hill Areas of Lalitpur District, Nepal." Journal of Agriculture and Natural 
Resources 3(1): 117-32

16. Boyce MS, Vernier PR, Nielsen SE, Schmiegelow FKA (2002) Evaluating Resource Selection Functions. Ecol Model 157:281-300

17. Breiner FT, Guisan A, Bergamini A, Nobis MP (2015) Overcoming Limitations of Modelling Rare Species by Using Ensembles of Small Models. Methods Ecol Evol 6(10):1210-1218

18. Breiner FT, Nobis MP, Bergamini A, Guisan A (2018) Optimizing Ensembles of Small Models for Predicting the Distribution of Species with Few Occurrences. Methods Ecol Evol 9(4):802-808

19. Broennimann O et al (2007) Evidence of Climatic Niche Shift during Biological Invasion. Ecol Lett 10(8):701-709

20. Broennimann O, Cola VD, Guisan A (2020) “Ecospat: Spatial Ecology Miscellaneous Methods.” $R$ package version 3.1. https://CRAN.R-project.org/package=ecospat

21. CAIB. 2019. “Las Illes Balears Se Convierten En El Primer Territorio Europeo Que Consigue Erradicar La Avispa Asiática." https://www.caib.es/pidip2front/jsp/es/ficha-noticia/strongstronglasistrongstrongllesstrongstrong-balears-se-convierten-en-el-primer-territorio-europeo-que-consigueerradicar-la-avispa-asiaacuteticastrongstrong0 (June 8, 2021)

22. Carvalho J et al (2020) Patterns of Vespa Velutina Invasion in Portugal Using Crowdsourced Data. Insect Conservation Diversity 13(5):501-507

23. Clusa L et al (2018) "Public Knowledge of Alien Species: A Case Study on Aquatic Biodiversity in North Iberian Rivers.” Journal for Nature Conservation 42(April 2017): 53-61. https://doi.org/10.1016/j.jnc.2018.01.001

24. Di Cola, Valeria et al (2017) Ecospat: An R Package to Support Spatial Analyses and Modeling of Species Niches and Distributions. Ecography 40(6):774-787

25. Dainat B, vanEngelsdorp D, Neumann P (2012) Colony Collapse Disorder in Europe. Environmental Microbiology Reports 4(1):123-125

26. Elith J, Ferrier S, Huettmann F, and John Leathwick (2005) The Evaluation Strip: A New and Robust Method for Plotting Predicted Responses from Species Distribution Models. Ecol Model 186(3):280289

27. Elith J, Kearney M, and Steven Phillips (2010) The Art of Modelling Range-Shifting Species. Methods Ecol Evol 1(4):330-342

28. Ellis JD, Evans JD, and Jeff Pettis (2010) Colony Losses, Managed Colony Population Decline, and Colony Collapse Disorder in the United States. J Apic Res 49(1):134-136

29. Di Febbraro, Mirko et al (2019) Integrating Climate and Land-Use Change Scenarios in Modelling the Future Spread of Invasive Squirrels in Italy. Divers Distrib 25(4):644-659

30. Fitzpatrick MC, Jake F, Weltzin NJ, Sanders, Dunn RR (2006) The Biogeography of Prediction Error: Why Does the Introduced Range of the Fire Ant over-Predict Its Native Range? Glob Ecol Biogeogr 0(0):061120101210019-061120101210019??? 
31. Fournier A, Barbet-Massin M, Rome Q, and Franck Courchamp (2017) Predicting Species Distribution Combining Multi-Scale Drivers. Global Ecology Conservation 12:215-226. https://doi.org/10.1016/j.gecco.2017.11.002

32. Franklin DN et al (2017) Invasion Dynamics of Asian Hornet, Vespa Velutina (Hymenoptera: Vespidae): A Case Study of a Commune in South-West France. Appl Entomol Zool 52(2):221-229

33. Graham EA, Henderson S, and Annette Schloss (2011) Using Mobile Phones to Engage Citizen Scientists in Research. Eos 92(38):313-315

34. Guisan A, and Wilfried Thuiller (2005) Predicting Species Distribution: Offering More than Simple Habitat Models. Ecol Lett 8(9):993-1009

35. de Haro L et al (2010) Medical Consequences of the Asian Black Hornet (Vespa Velutina) Invasion in Southwestern France. Toxicon 55(2-3):650-652

36. Harrell FE, Lee KL, Mark DB (1996) Multivariable Prognostic Models: Issues in Developing Models, Evaluating Assumptions and Adequacy, and Measuring and Reducing Errors. Statisticas in medicine 15:361-387

37. Haxaire J, Bouguet J-P, Jean-Philippe Tamisier (2006) Vespa Velutina Lepeletier, 1836, Une Redoutable Nouveauté Pour La Faune de France (Hym., Vespidae). Bulletin de la Société entomologique de France 111(2):194-194

38. Hernandez PA, Catherine H, Graham LL, Master, Albert DL (2006) The Effect of Sample Size and Species Characteristics on Performance of Different Species Distribution Modeling Methods. Ecography 29(5):773-785

39. Herrera C, Leza M, Emma, Martínez-López (2020) Diversity of Compounds in Vespa Spp. Venom and the Epidemiology of Its Sting: A Global Appraisal. Arch Toxicol 94(11):3609-3627. https://doi.org/10.1007/s00204-020-02859-3

40. Hirzel AH, Gwenaëlle LL (2008) Habitat Suitability Modelling and Niche Theory. J Appl Ecol 45(5):1372-1381

41. Holden MH, Jan P, Nyrop, and Stephen P. Ellner (2016) The Economic Benefit of Time-Varying Surveillance Effort for Invasive Species Management. J Appl Ecol 53(3):712-721

42. Hudgins EJ, Liebhold AM, and Brian Leung (2017) Predicting the Spread of All Invasive Forest Pests in the United States. Ecol Lett 20(4):426-435

43. Ikegami M et al (2020) Environments, Spatial Structures, and Species Competitions: Determining the Impact of Yellow-Legged Hornets, Vespa Velutina, on Native Wasps and Bees on Tsushima Island, Japan. Biol Invasions 22(10):3131-3143. https://doi.org/10.1007/s10530-020-02314-5

44. Janekovi F, Novak T (2012) "PCA - A Powerful Method for Analyze Ecological Niches". In: Sanguansat P (ed) Principal Component Analysis - Multidisciplinary Applications. InTech, Rijeka, pp 128-142

45. Johnson CJ, Gillingham MP (2005) An Evaluation of Mapped Species Distribution Models Used for Conservation Planning. Environ Conserv 32(2):117-128 
46. Klemann-Junior L, Vallejos MAlejandroV, Scherer-Neto P, Ricardo Simöes J Vitule (2017) "Traditional Scientific Data Vs. Uncoordinated Citizen Science Effort: A Review of the Current Status and Comparison of Data on Avifauna in Southern Brazil." PLoS ONE 12(12): 1-27

47. Lassueur T, Joost S, Randin CF (2006) Very High Resolution Digital Elevation Models: Do They Improve Models of Plant Species Distribution? Ecol Model 198(1-2):139-153

48. Laurino D et al (2020) "Vespa Velutina: An Alien Driver of Honey Bee Colony Losses." Diversity 12(1)

49. Lester PJ, Beggs JR (2018) "Invasion Success and Management Strategies for Social Vespula Wasps." Annual Review of Entomology 64(September 2018): 51-71

50. Levine JM, Carla M, D’Antonio (2003) Forecasting Biological Invasions with Increasing International Trade. Conserv Biol 17(1):322-326

51. Leza M et al (2021) Six Years of Controlling the Invasive Species Vespa Velutina in a Mediterranean Island: The Promising Results of an Eradication Plan. Pest Manag Sci 77(5):2375-2384

52. Leza M, Miguel Ángel Miranda, and Víctor Colomar (2018) "First Detection of Vespa Velutina Nigrithorax (Hymenoptera: Vespidae) in the Balearic Islands (Western Mediterranean): A Challenging Study Case." Biological Invasions 20(7): 1643-49

53. Lioy S et al (2019) Establishing Surveillance Areas for Tackling the Invasion of Vespa Velutina in Outbreaks and over the Border of Its Expanding Range. NeoBiota 69(46):51-69

54. MAGRAMA (2015) Estrategia de Gestión, Control y Posible Erradicación Del Avispón Asiático o Avispa Negra (Vespa Velutina Ssp. Nigrithorax) En España. Madrid. https://www.miteco.gob.es/es/biodiversidad/publicaciones/estrategia_vespavelutina_tcm3069976.pdf

55. de Medeiros CM, Hernández-Lambraño RE, Sánchez J Agudo (2018) How Reliable Is the Untrained Eye in the Identification of an Invasive Species? The Case of Alien Bee-Hawking Yellow-Legged Hornet in Iberian Peninsula. Contemporary Problems of Ecology 11(6):666-681

56. Moller H (1996) Lessons for Invasion Theory from Social Insects. Biol Cons 78(1-2):125-142

57. Monceau K, Bonnard O, Thiéry D (2014) Vespa Velutina: A New Invasive Predator of Honeybees in Europe. J Pest Sci 87(1):1-16

58. Monceau K, Maher N, Bonnard O, Thiéry D (2013) Predation Pressure Dynamics Study of the Recently Introduced Honeybee Killer Vespa Velutina: Learning from the Enemy. Apidologie 44(2):209-221

59. Monceau K, and Denis Thiéry (2016) Vespa Velutina Nest Distribution at a Local Scale: An 8-Year Survey of the Invasive Honeybee Predator. Insect Science 0(0):1-12

60. Muirhead JR et al (2006) Modelling Local and Long-Distance Dispersal of Invasive Emerald Ash Borer Agrilus Planipennis (Coleoptera) in North America. Divers Distrib 12(1):71-79

61. Newson R (2006) Confidence Intervals for Rank Statistics: Somers' D and Extensions. Stata Journal 6(3):309-334 
62. Paini DR et al (2016) Global Threat to Agriculture from Invasive Species. Proc Natl Acad Sci USA 113(27):7575-7579

63. Pearman PB, Guisan A, Broennimann O, Christophe FR (2008) Niche Dynamics in Space and Time. Trends in Ecology Evolution 23(3):149-158

64. Pearson RG, Christopher J, Raxworthy M, Nakamura, Townsend Peterson A (2007) Predicting Species Distributions from Small Numbers of Occurrence Records: A Test Case Using Cryptic Geckos in Madagascar. J Biogeogr 34(1):102-117

65. Peterson A, Townsend M, Papes, Kluza DA (2003) Predicting the Potential Invasive Distributions of Four Alien Plant Species in North America. Weed Sci 51(6):863-868

66. Peterson A, Townsend, and C. Richard Robins (2003) Using Ecological-Niche Modeling to Predict Barred Owl Invasions with Implications for Spotted Owl Conservation. Conserv Biol 17(4):1161-1165

67. Pusceddu M et al (2019) Using Verified Citizen Science as a Tool for Monitoring the European Hornet (Vespa Crabro) in the Island of Sardinia (Italy). NeoBiota 50:97-108

68. Pyron R, Alexander, Frank T, Burbrink, and Timothy J. Guiher (2008) Claims of Potential Expansion throughout the U.S. by Invasive Python Species Are Contradicted by Ecological Niche Models. PLoS ONE 3(8):1-7

69. Requier $\mathrm{F}$ et al (2019) Predation of the Invasive Asian Hornet Affects Foraging Activity and Survival Probability of Honey Bees in Western Europe. J Pest Sci 92(2):567-578.

https://doi.org/10.1007/s10340-018-1063-0

70. Robinet C, Eric Darrouzet, and Christelle Suppo (2019) Spread Modelling: A Suitable Tool to Explore the Role of Human-Mediated Dispersal in the Range Expansion of the Yellow-Legged Hornet in Europe. International Journal of Pest Management 65(3):258-267.

https://doi.org/10.1080/09670874.2018.1484529

71. Robinet C, Suppo C, and Eric Darrouzet (2017) Rapid Spread of the Invasive Yellow-Legged Hornet in France: The Role of Human-Mediated Dispersal and the Effects of Control Measures. J Appl Ecol 54(1):205-215

72. Rodríguez-Flores M, Shantal A, Seijo-Rodríguez O, Escuredo, María del Carmen Seijo-Coello (2019) "Spreading of Vespa Velutina in Northwestern Spain: Influence of Elevation and Meteorological Factors and Effect of Bait Trapping on Target and Non-Target Living Organisms." J Pest Sci 92(2): 557-565. https://doi.org/10.1007/s10340-018-1042-5

73. Rojas-Nossa SV, María C-C (2020) The Invasive Hornet Vespa Velutina Affects Pollination of a Wild Plant through Changes in Abundance and Behaviour of Floral Visitors. Biol Invasions 22(8):26092618

74. Rome Q, Perrard A, Muller F, and Claire Villemant (2011) Monitoring and Control Modalities of a Honeybee Predator, the Yellow-Legged Hornet Vespa Velutina Nigrithorax (Hymenoptera- Vespidae). Aliens: The Invasive Species Bulletin 31:7-15

75. Sardain A, Erik Sardain, and Brian Leung (2019) Global Forecasts of Shipping Traffic and Biological Invasions to 2050. Nature Sustainability 2(4):274-282. http://dx.doi.org/10.1038/s41893-019-0245- 
76. Scherrer D, Christe P, and Antoine Guisan (2019) Modelling Bat Distributions and Diversity in a Mountain Landscape Using Focal Predictors in Ensemble of Small Models. Divers Distrib 25(5):770782

77. Sears MW, Raskin E, and Michael J. Angilletta (2011) The World Is Not Flat: Defining Relevant Thermal Landscapes in the Context of Climate Change. Integr Comp Biol 51(5):666-675

78. Somodi I, Lepesi N, Zoltán B-D (2017) Prevalence Dependence in Model Goodness Measures with Special Emphasis on True Skill Statistics. Ecology Evolution 7(3):863-872

79. Song Y, Gang et al (2019) "Predicting Climate Change Impacts on the Threatened Quercus Arbutifolia in Montane Cloud Forests in Southern China and Vietnam: Conservation Implications." Forest Ecology and Management 444(December 2018): 269-79. https://doi.org/10.1016/j.foreco.2019.04.028

80. Thuiller W, Lafourcade B, Engler R, Araújo MB (2009) BIOMOD - A Platform for Ensemble Forecasting of Species Distributions. Ecography 32(3):369-373

81. Traveset A, Escribano-Avila G, Gómez JM, and Alfredo Valido (2019) Conflicting Selection on Cneorum Tricoccon (Rutaceae) Seed Size Caused by Native and Alien Seed Dispersers. Evolution 73(11):2204-2215

82. Turchi L, Derijard B (2018) Options for the Biological and Physical Control of Vespa Velutina Nigrithorax (Hym.: Vespidae) in Europe: A Review. J Appl Entomol 142(6):553-562

83. Vaughan IP, Ormerod SJ (2005) The Continuing Challenges of Testing Species Distribution Models. J Appl Ecol 42(4):720-730

84. Villemant $C$ et al (2011) Predicting the Invasion Risk by the Alien Bee-Hawking Yellow-Legged Hornet Vespa Velutina Nigrithorax across Europe and Other Continents with Niche Models. Biol Cons 144(9):2142-2150. http://dx.doi.org/10.1016/j.biocon.2011.04.009

85. Villemant C, Muller F, Haubois S (2011) "Bilan Des Travaux (MNHN et IRBI) Sur l'invasion En France de Vespa Velutina, Le Frelon Asiatique Prédateur d'abeilles." Journée Scientifique Apicole: 3-12. http://inpn.mnhn.fr/docs/Vespa_velutina/2011_02_11_Bilan_Invasion_Vespa_velutina_JSA.pdf

86. Virtanen EA, Viitasalo M, Lappalainen J, and Atte Moilanen (2018) Evaluation, Gap Analysis, and Potential Expansion of the Finnish Marine Protected Area Network. Frontiers in Marine Science 9(NOV):1-19

87. Zengeya TA, Mark P, Robertson AJ, Booth, Chimimba CT (2013) Ecological Niche Modeling of the Invasive Potential of Nile Tilapia Oreochromis Niloticus in African River Systems: Concerns and Implications for the Conservation of Indigenous Congenerics. Biol Invasions 15(7):1507-1521

\section{Figures}






Figure 1

Differences in accuracy (AUC, Boyce, SomersD and TSS) between the ten different models used in this study and the final ensemble model (EF). Artificial neural network (ANN), Classification tree analysis (CTA), Final Ensemble (EF), Flexible Discriminant Analysis (FDA), Generalized additive models (GAM), Generalized boosting method (GBM), Generalized linear models (GLM), Multivariate adaptive regression spline (MARS), Random forest (RF) and Surface Range Envelope (SRE). 


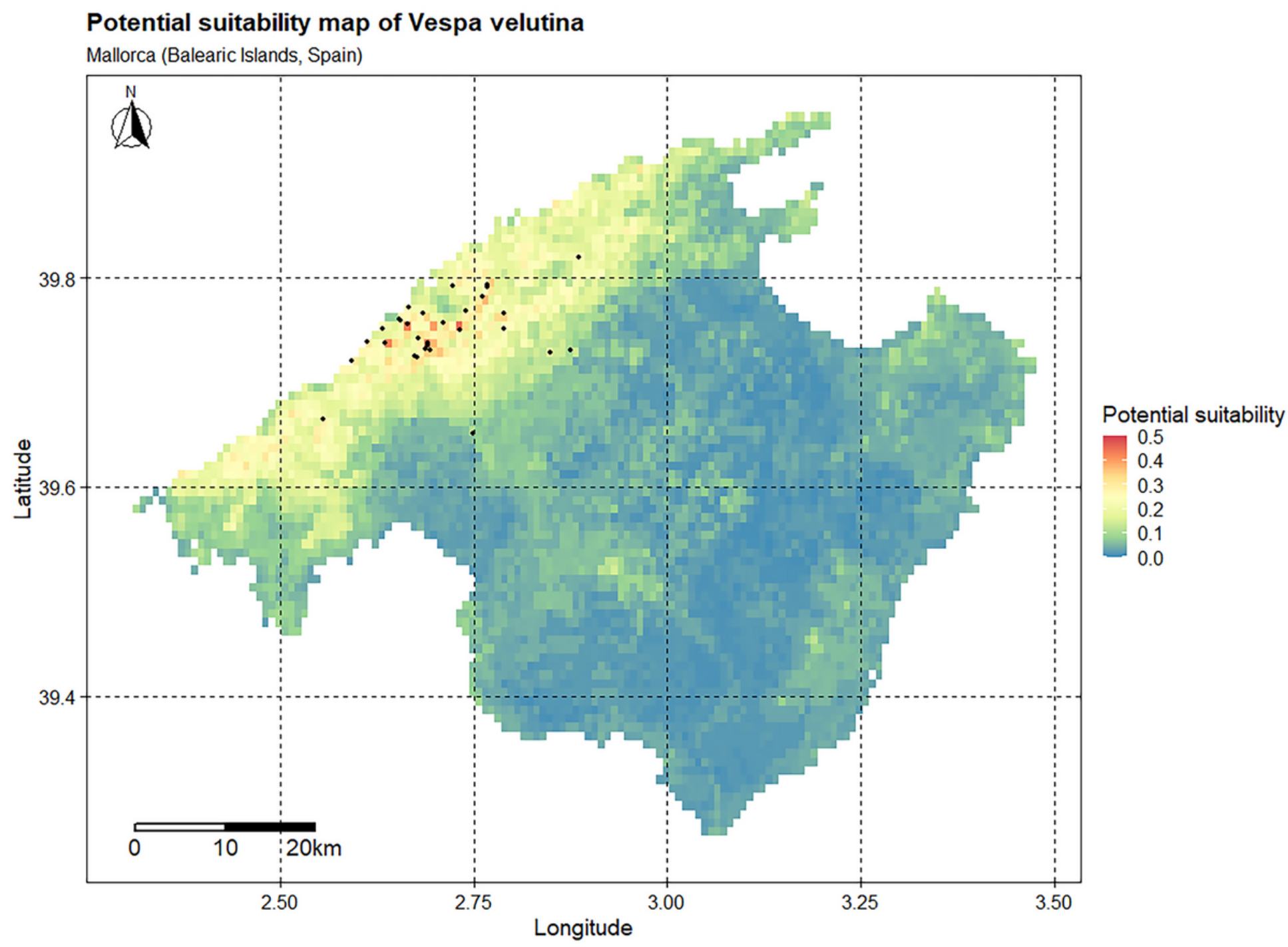

Figure 2

Vespa velutina sites (black dots) used to calibrate the models and habitat suitability under Mediterranean island conditions. Potential suitability is represented in a colour scale from red (high values) to blue (low values). 

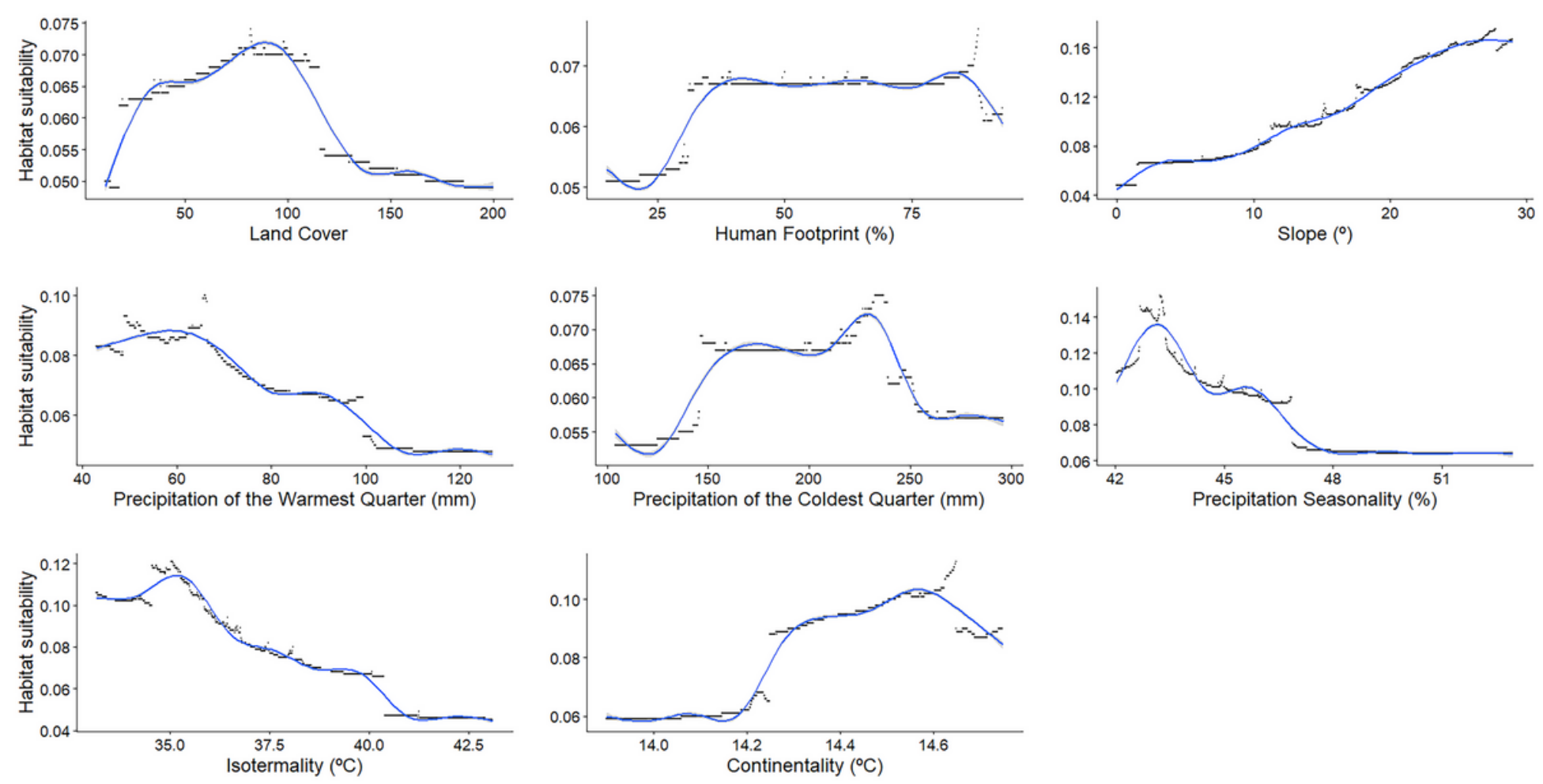

\section{Figure 3}

Response curves of the habitat suitability final ensemble model of Vespa velutina under Mediterranean island conditions. 

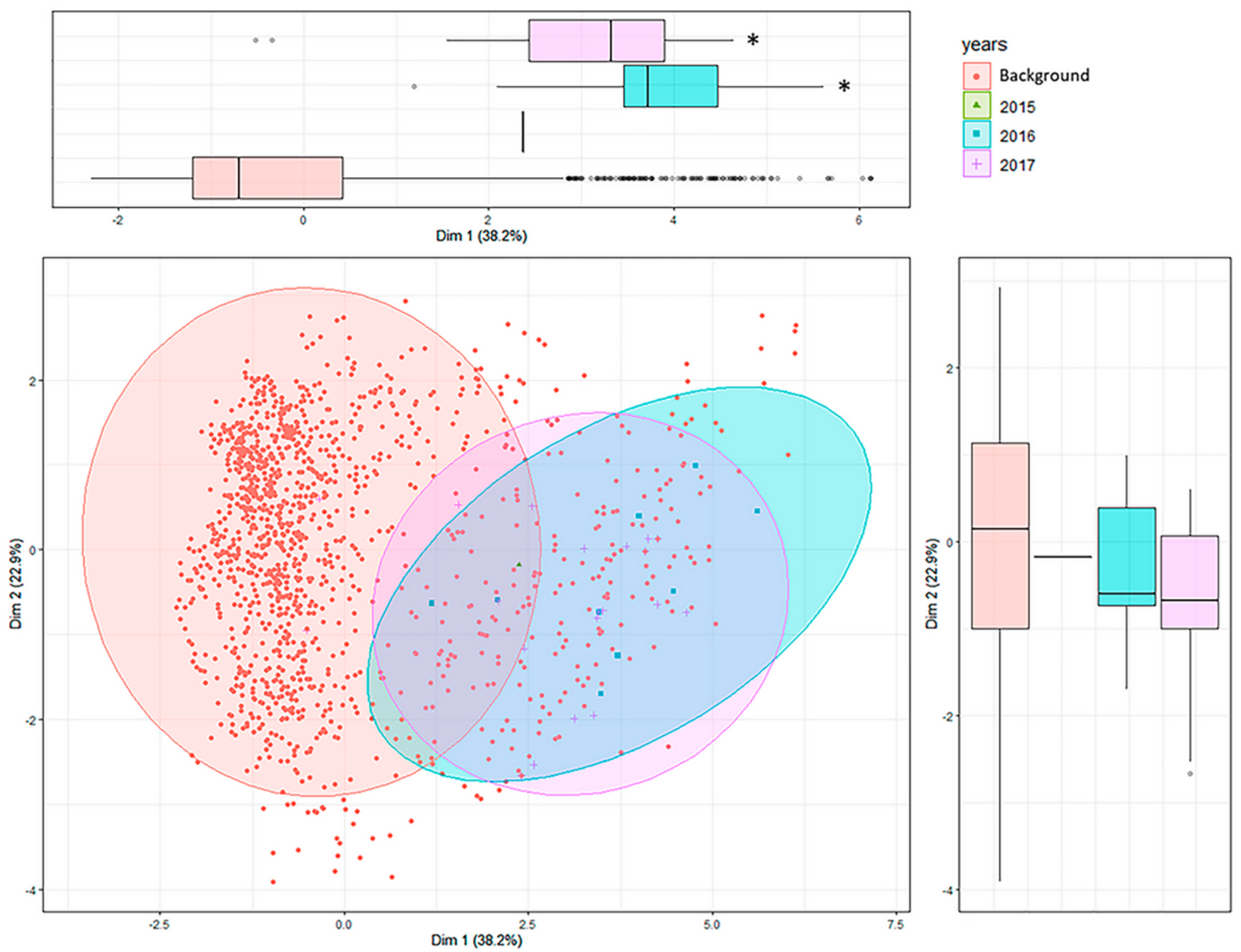

\section{Figure 4}

Principal components analysis (2D-PCA) with ellipses (95\% confidence) and marginal box plots showing Vespa velutina niche under Mediterranean island conditions. The position of occurrences, from the invaded range along the three years with active invasion is indicated in green (2015), blue (2016) and pink dots (2017) and the background is indicated in red dots, respectively. Statistically significant difference between $\mathrm{V}$. velutina niche and background in marginal box plots (Kruskal-Wallis test, *p-value < 0.05). 2015 based in only one nest. 

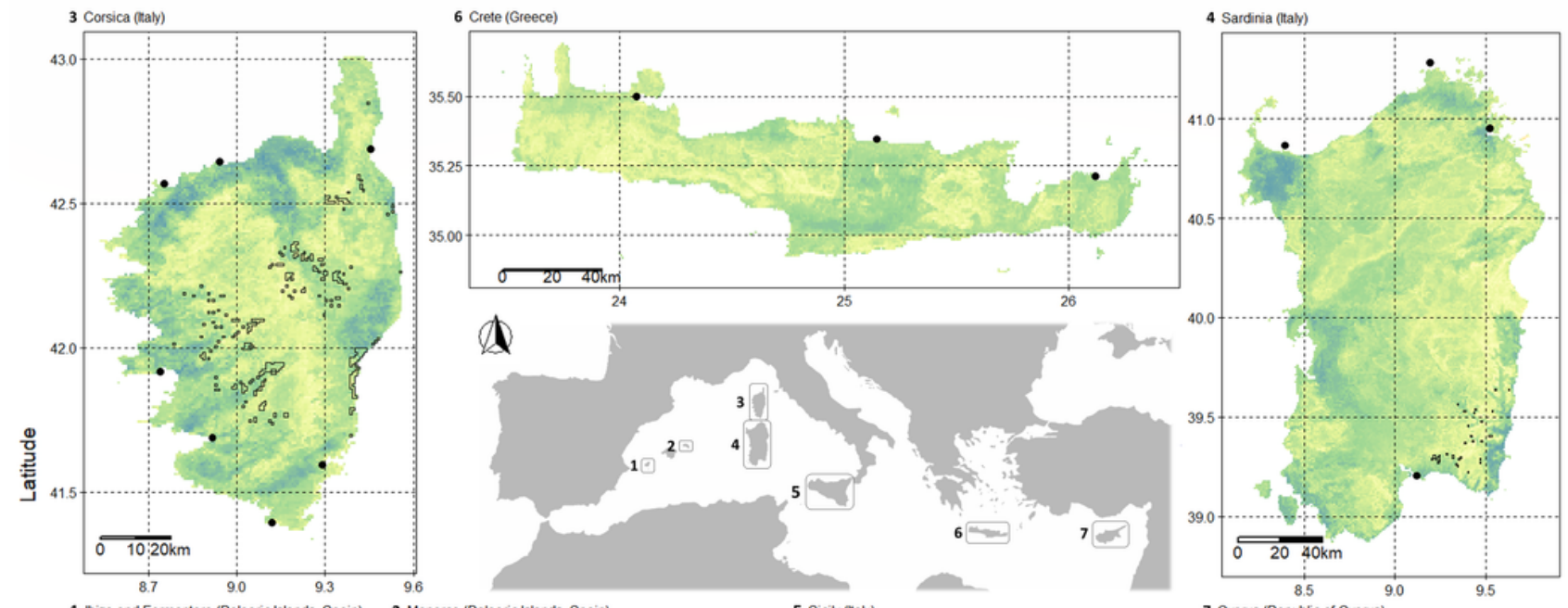

Potential suitability
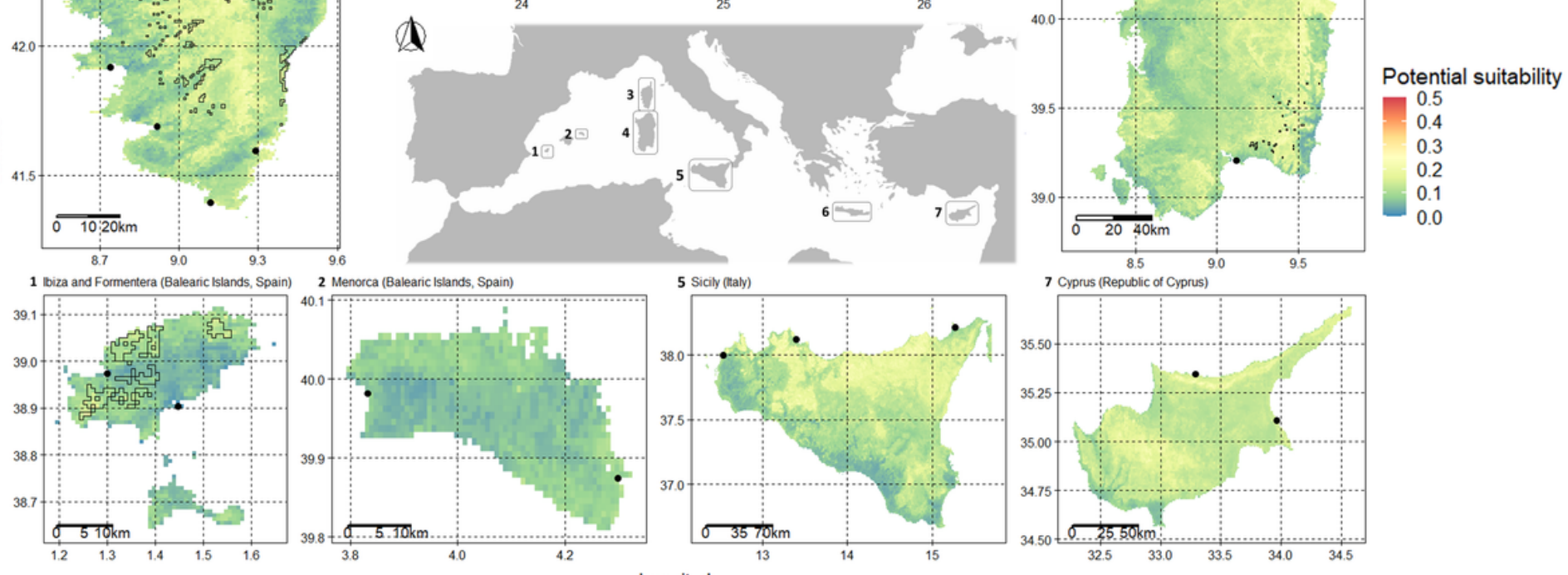

\section{Figure 5}

Transferability of the potential suitability in the biggest Mediterranean islands for V. velutina. Potential suitability is represented in a colour scale from red (high values) to blue (low values) and ports are represented as black dots. Multivariate Environmental Similarity Surface (MESS) results are represented in dark polygons, determining areas with similar conditions to the calibration conditions of the model in Mallorca.

\section{Supplementary Files}

This is a list of supplementary files associated with this preprint. Click to download.

- Supplementarymaterial.docx 